\title{
Lawrence J. Doctors: Hydrodynamics of high-performance marine vessels
}

\author{
Create Space (an Amazon.com company), Charleston, SC (2015), Vols. 1 and 2
}

\section{R. Cengiz Ertekin ${ }^{1}$}

Published online: 5 April 2016

(C) Springer International Publishing Switzerland 2016

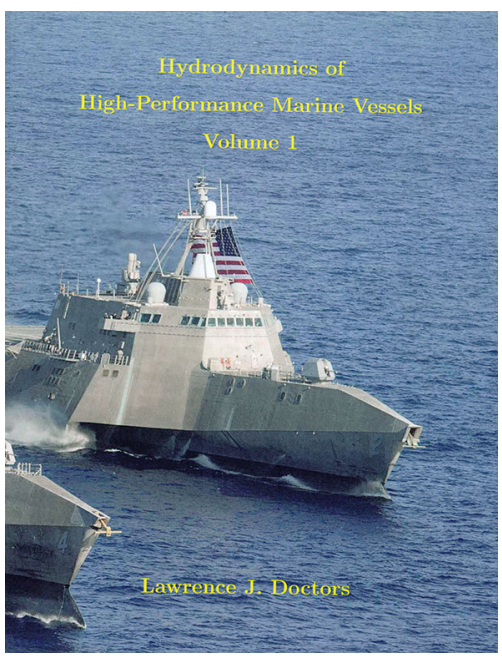

This is a two volume book on the hydrodynamics of highspeed marine vessels recently authored by Prof. Lawrence J. Doctors of the University of New South Wales, Australia. The two volumes (collectively called the "book" here) consist of $836+$ pages and 17 chapters, along with an extensive bibliography and index, and an Appendix that also includes a glossary of terms, measurement systems and mathematical formulas. In the beginning pages, detailed lists of figures, tables and symbols are given, and these and the index at the end make the book very easy to follow. I have found the inclusion of many photographs of various high-speed vessels very educational.

Communicated by Umesh A. Korde.

R. Cengiz Ertekin ertekin@hawaii.edu

1 Department of Ocean and Resources Engineering, University of Hawaii, Honolulu, HI 96822, USA
Among others, high-speed vessels include air-cushion vehicles, multihulls, surface-effect ships and planing crafts. The hydrodynamics of these types of vessels often employs the potential theory based on the ideal-fluid assumption but also considers the effect of viscosity, at times in an empirical way. As such, theoretical and numerical concepts and experimental studies are all considered in the book. And this broad coverage makes the book a very good one to refer to for those of us who study the forces (including the resistance) acting on and the motions of such vessels.

The first Volume opens with an introductory chapter that includes the topic of dimensional analysis, although very briefly. If the study of dimensional analysis is of importance to the reader, other books need to be consulted. This is followed by a chapter on hydrodynamic theory, mostly for an incompressible and inviscid fluid and irrotational flow. Chapter 3 is on viscous resistance and includes a wealth of experimental data for various hull forms. This chapter is concluded with a discussion on aerodynamic drag, and it is followed by a chapter on transom sterns preferred for most displacement vessels. In the following three chapters, wave resistance of monohulls, catamarans, and trimarans and other multihulls are discussed, mainly in terms of potential flow due to a point source traveling at constant speed. Any type of mono or multihull is treated uniformly with the same theoretical approach. Experimental data nicely accompany the calculations. The historical developments on air-cushion vehicles around the world are extensively covered in Chapter 8 that also includes the discussion of wave resistance both theoretically and experimentally. The book is mostly founded on linear theory but Chapter 8 includes a discussion on the effect of nonlinearities for moving pressure patches in otherwise unrestricted waters on the horizontal plane. Volume 1 ends with two chapters on skirts and seals and surface-effect ships. 
The second volume opens with Chapter 11 on planing crafts; theoretical, numerical (in the form of computational fluid dynamics approach) and experimental methods are discussed. This is followed by a chapter on wave generation for displacement and other types of vessels such as air-cushion, surface-effect and planing hulls within the context of linear and nonlinear systems. Squat is the subject of Chapter 13 and is followed in the next chapter by unsteady effects on resistance and wave generation. In this and many other chapters, the effect of water depth is taken into account as well as the presence of any possible channel walls for vessels moving in restricted waters, except in Chapter 15 that is on motions of displacement vessels in waves. Irregular-sea motion response is briefly discussed in Chapter 15, and this is followed by motions of nondisplacement vessels in waves in Chapter 16. The book is completed with an Appendix that also contains a Glossary that should be useful to students, although a few of the definitions need to be revised, e.g., that an incompressible fluid is "a fluid with fixed density", rather than "a fluid for which the material derivative of density vanishes". The bibliography and the index are impressive; two features of this book that many of us should learn from.

In summary, what is especially impressive about the book is that it will be equally useful to academics and practitioners, a rather rare writing by a prominent scholar, and the presentation is very clear and elegant. This is a book destined to be a classic. I highly recommend the book to students, researchers and engineers who, I am sure, would find it an invaluable source of information, not only on the hydrodynamics of high-speed vessels, but also on marine hydrodynamics in general. 